\title{
DIMINUTION IN RENAL ALKALINE PHOSPHATASE IN ENDOTOXIN SHOCK
}

\author{
By WESLEY W. SPINK AND MARY JEAN LANDERYOU \\ (From the Department of Medicine, University of Minnesota Hospitals and Medical School, \\ Minneapolis, Minn.)
}

(Submitted for publication July 29, 1959; accepted September 25, 1959)

Generalized and severe vasoconstriction is promptly induced when endotoxin is introduced into the blood stream of animals (1). This initial vasospasm is often followed shortly by vasodilation and peripheral vascular failure. An added feature of endotoxin shock is the frequent appearance of renal failure, often followed by oliguria, anuria, uremia, and death.

Because renal failure is such a grave complication in patients with shock and bacteremia caused by gram-negative bacteria, we have carried out studies on animals in order to obtain more information on the nature of the renal failure occurring in endotoxin shock. In the first series of studies, anesthetized eviscerated dogs were employed in such a manner that the weight of a kidney could be correlated with renal blood flow and urinary output (2). The exposed kidney still attached to its pedicle was loosely suspended by the capsule to a weighing device so that weight changes could be traced on a Sanborn Poly Viso recorder. Within a few seconds after the injection of $E s$ cherichia coli endotoxin into the animal, and even before the appearance of hypotension, a pronounced diminution in renal blood occurred, which was reflected in a reduction in kidney weight. The maximum reduction in weight averaged 25 per cent, and took place within 10 to 20 minutes. Coincident with this reduction in weight the flow of urine ceased. These studies on renal function produced by endotoxin were investigated further in the isolated heart-lung-kidney preparation of the $\operatorname{dog}(3)$. It was concluded that the primary actions of endotoxin on the kidney were due to vasoconstriction and to a reduced renal blood flow.

While the ischemia and anoxia of the kidney that are produced by endotoxin cause a rapid reduction in renal function, which may be irreversible, very few or no morphologic changes can be detected during the early stages by the usual histologic techniques. The degree of discernible renal damage induced by ischemia is dependent upon the period of time during which the ischemia and anoxia persist $(4,5)$. This has been demonstrated in human subjects with acute renal failure in whom serial renal biopsies have been carried out (6).

Since we had observed in human subjects and in experimental animals with fatal endotoxin shock a lack of correlation between severe renal failure and morphologic changes in the kidney, the possibilities of employing histochemical techniques in order to detect changes were explored. Since it had been well established that the enzyme, alkaline phosphatase, was present in abundance in the kidneys of many mammalian species, including humans, the renal ischemia and anoxia caused by endotoxin were correlated with the amount of phosphatase present in the renal tissue. It is significant that the alkaline phosphatase is particularly abundant in the region of the proximal convoluted tubules, and it is this area that is especially vulnerable to the effects of ischemia $(7,8)$. Beyer (9) has pointed out that alkaline phosphatase is found in the brush borders of the tubule cells and in the luminal membrane, while the acid phosphatase exists in a more diffuse pattern on the interstitial side of the cells. Brain and Kay (10) made quantitative determinations on alkaline phosphatase in human kidneys and found a marked diminution in those instances in which severe renal disease was present. They also found a marked reduction of alkaline phosphatase in the kidneys of rabbits in which tubular damage followed the injection of uranyl nitrate. Others (11) reported a reduction in the alkaline phosphatase of abnormal human kidneys, including the kidneys from one case of traumatic shock. Wilmer (12) found less phosphatase in the kidneys of rabbits following the mechanical production of renal ischemia.

In the present investigation the distribution 
of alkaline phosphatase was studied in kidneys of patients dying from causes other than renal failure, and also of patients dying from shock and renal failure. The patients dying from shock included some who had bacteremia and renal failure caused by gram-negative bacteria. In addition, serial studies on alkaline phosphatase were carried out in the kidneys of dogs, rabbits, guinea pigs, rats and mice, that had been given $E$. coli endotoxin.

\section{METHODS}

Demonstration of alkaline phosphatase. Gomori's technique, as described by Lillie (13), was employed for demonstrating phosphatase. The phosphatase was demonstrated by a staining technique rather than by quantitative chemical titrations because it was desirable to detect the distribution of phosphatase in the kidney after the appearance of shock. It was surmised that the vasoconstriction might be segmental and, as a consequence, there would be a segmental ischemia and anoxia. A segmental distribution of phosphatase would then be anticipated. This segmental distribution was clearly demonstrated in the experiments to be reported in this communication. Shortly after death of the patient, sections of the kidney were fixed in alcohol for the demonstration of phosphatase, and in formalin for comparative histologic examination of tissue stained with hematoxylin and eosin. In the case of animals to which endotoxin had been given, both kidneys were removed immediately after death and fixed for phosphatase and for staining with hematoxylin and eosin. It was observed in preliminary studies that reliable comparative studies for phosphatase could only be made when all of the tissues were sectioned and stained at the same time. Therefore, all of the kidney sections of a given species which had received endotoxin, with appropriate controls, were sectioned and stained simultaneously.

Endotoxin. One lot of E. coli endotoxin was used throughout. ${ }^{1}$ The dose of endotoxin selected was sufficient to produce shock, but death did not always result. Those animals that did not die from shock were sacrificed at intervals to be noted.

Swiss-Webster male mice weighing approximately $20 \mathrm{~g}$ were given $0.025 \mathrm{mg}$ of endotoxin intraperitoneally and sacrificed 16 and 48 hours later. This dose of endotoxin was not lethal within this period.

Unanesthetized stock guinea pigs averaging $250 \mathrm{~g}$ were the subjects of 2 experiments. In the first group, a nonlethal dose of $0.75 \mathrm{mg}$ of endotoxin per $\mathrm{kg}$ of weight was given intraperitoneally. The second group received $1.5 \mathrm{mg}$ per $\mathrm{kg}$, which proved lethal within 6 to 8 hours.

Sprague-Dawley male rats weighing 300 to $500 \mathrm{~g}$ were given $10 \mathrm{mg}$ of endotoxin per $250 \mathrm{~g}$ intravenously, in the tail vein. This dose was sufficient to produce a severe state of vasoconstriction that could be readily detected in

1 Difco Labs, Inc., Lot no. 206B6. the ears and paws. Death occurred within 6 to 8 hours after the injection of endotoxin.

Two schedules of doses were used in unanesthetized stock rabbits weighing 3 to $5 \mathrm{~kg}$. In one experiment, 3 mg per $\mathrm{kg}$ of body weight was administered through an ear vein, and in a second experiment $5 \mathrm{mg}$ per $\mathrm{kg}$ was given. Both of these doses were lethal for the majority of animals within 8 to 12 hours.

Mongrel dogs weighing 8 to $10 \mathrm{~kg}$ were anesthetized with $30 \mathrm{mg}$ of sodium pentobarbital (Nembutal) per $\mathrm{kg}$ of body weight before receiving an intravenous injection of $0.1 \mathrm{mg}$ of endotoxin per $\mathrm{kg}$. This dose, although not uniformly lethal, was sufficient to produce severe shock. Kidneys were studied in those animals which had either died or had been sacrificed 2 to 48 hours after having received endotoxin.

\section{RESULTS}

\section{Alkaline phosphatase in human kidneys}

Phosphatase in the kidneys of 14 patients was determined in a semiquantitative manner by grading from 0 to $4+$, as seen in Table I. The ages of these subjects ranged from a fetus of 5.5 months to an adult 81 years of age. Two patients (Cases 2 and 3 ), dying from carcinoma, had kidneys with maximum amounts of phosphatase. The section of kidney from Case 2 is shown in Figure 1. This is to be compared with the findings in Case 14 , which represents a young adult male who suffered from burns and shock due to a bacteremia with Pseudomonas aeruginosa. As seen in Figure 2, no phosphatase was demonstrated in this patient's kidneys. We have confirmed the observation that the very young have normal kidneys containing less phosphatase than the kidneys of normal adults. Cases 1 and 6 represent a fetus of 5.5 months and an infant 6 months of age, respectively.

The kidneys from patients dying from shock and renal failure as a result of hemorrhage, myocardial infarction or sepsis, all had reduced amounts of phosphatase. In addition, one patient (Case 10), with chronic glomerulonephritis and uremia, had kidneys without any demonstrable phosphatase.

The findings in Patients 12 and 13 are of particular interest. Both of these had had severe renal failure and shock induced by bacteremia. The blood pressures in each were maintained for several days with pressor amines. Adrenocorticosteroids were also administered to them. Although the blood pressures were stabilized, and the 
TABLE I

Study of alkaline phosphatase in human kidneys

\begin{tabular}{|c|c|c|c|c|}
\hline $\begin{array}{l}\text { Patient } \\
\text { no. }\end{array}$ & Age and sex & Cause of death & $\begin{array}{l}\text { Alkaline } \\
\text { phosphatase* }\end{array}$ & $\begin{array}{l}\text { Sections stained with hematoxylin } \\
\text { and eosin }\end{array}$ \\
\hline 1 & Fetus $-5.5 \mathrm{mo}$ & $\begin{array}{l}\text { Spontaneous abortion; lived } \\
4 \text { hours }\end{array}$ & ++ & Normal \\
\hline $\begin{array}{l}2 \\
3\end{array}$ & $\begin{array}{ll}25 & \mathrm{~F} \\
62 & \mathrm{M}\end{array}$ & $\begin{array}{l}\text { Cancer of breast } \\
\text { Cancer of esophagus }\end{array}$ & $\begin{array}{l}++++ \\
+++\end{array}$ & $\begin{array}{l}\text { Normal } \\
\text { Arteriosclerotic changes; occasional hya- } \\
\text { line glomerulus }\end{array}$ \\
\hline $\begin{array}{l}4 \\
5\end{array}$ & $\begin{array}{ll}56 & \mathrm{~F} \\
23 & \mathrm{~F}\end{array}$ & $\begin{array}{l}\text { Cancer of colon } \\
\text { Pneumonia }\end{array}$ & $\begin{array}{c}++ \\
++\end{array}$ & $\begin{array}{l}\text { Slight arteriosclerotic changes } \\
\text { Normal }\end{array}$ \\
\hline 6 & $6 \mathrm{mo} \mathrm{M}$ & Subarachnoid hemorrhage & ++ & Normal \\
\hline 7 & $53 \mathrm{M}$ & Hemorrhagic shock & + & $\begin{array}{l}\text { Dilated proximal convoluted tubules; hy- } \\
\text { dropic vacuolization }\end{array}$ \\
\hline 8 & $66 \mathrm{M}$ & Hemorrhagic shock & + & Arteriosclerotic changes; dilated proximal \\
\hline 9 & $81 \mathrm{M}$ & $\begin{array}{l}\text { Acute myocardial infarct } \\
\text { with shock }\end{array}$ & + & Arteriosclerotic changes \\
\hline 10 & $55 \mathrm{M}$ & $\begin{array}{l}\text { Chronic glomerular nephritis } \\
\text { with uremia }\end{array}$ & 0 & $\begin{array}{l}\text { Severe hyalinization of glomeruli ; atrophy } \\
\text { of tubules }\end{array}$ \\
\hline 11 & $8 \mathrm{mo} \mathrm{F}$ & Acute sepsis with shock & + & Normal \\
\hline 12 & $55 \quad \mathrm{~F}$ & $\begin{array}{l}\text { Postoperative bacteremia } \\
\text { with shock }\end{array}$ & ++ & $\begin{array}{l}\text { Dilated proximal tubules; flattened epi- } \\
\text { thelial cells; casts }\end{array}$ \\
\hline 13 & $82 \mathrm{M}$ & $\begin{array}{l}\text { Cancer of bladder with shock } \\
\text { due to bacteremia (Pro- } \\
\text { teus) and hemorrhage }\end{array}$ & ++ & $\begin{array}{l}\text { Arteriosclerotic changes; dilated proximal } \\
\text { tubules; cellular infiltrate interstitial } \\
\text { tissue }\end{array}$ \\
\hline 14 & $28 \mathrm{M}$ & $\begin{array}{l}\text { Burns with shock due to } \\
\text { bacteremia (Pseudomonas } \\
\text { aeruginosa) }\end{array}$ & 0 & $\begin{array}{l}\text { Dilated tubules and flattened epithelial } \\
\text { cells }\end{array}$ \\
\hline
\end{tabular}

$*+=$ Trace of phosphatase $++++=$ maximum amount of phosphatase.

urinary output increased in both of these patients, they had uremia when they expired. The kidneys did not exhibit acute tubular necrosis, and the phosphatase content was only moderately decreased.

We have confirmed the observation that severe renal failure may be associated with few or no morphologic changes, as demonstrated with the
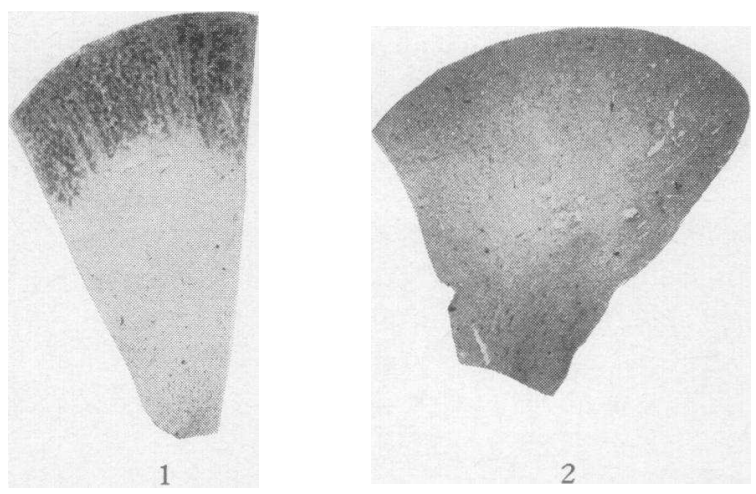

Fig. 1. Phosphatase in NORMal Kidney; $\times 5.5$

(CASE 2).

Fig. 2. Absence of phosphatase in Kidney of young ADULT MALE WHO DIED FROM SHOCK FOLLOWING SEVERE BURNS AND BACTEREMIA DUE TO PSEUDOMONAS AERUGINOSA ; $\times 5.5$ (CASE 14). hematoxylin and eosin stain. This was particularly evident in a case studied through the courtesy of Dr. Wendell Hall, and not included in Table 1. A young adult male was transfused with blood contaminated with Paracolobactrum aerogenoides. Shortly after the completion of the transfusion he developed shock and renal failure, and died 60 hours later. Microscopic examination of sections of his kidney (Figure 3 ) showed only slight dilatation and flattening of the tubules.

\section{Phosphatase studies in animals given endotoxin}

Mice. A group of ten Swiss-Webster mice were given a nonlethal dose of $E$. coli endotoxin intraperitoneally. The animals appeared to have fully recovered from the endotoxin when sacrificed 16 to 48 hours later. Figure 4 shows the distribution of phosphatase in the kidney of a normal Swiss-Webster mouse, while Figure 5 is representative of the slight amount of the enzyme present in the kidney of a mouse of the same species sacrificed 16 hours after receiving endotoxin. No morphologic changes were seen with hematoxylin and eosin stain in the kidneys of mice that had received endotoxin. It was concluded from this 
experiment that reversible shock produced in mice with endotoxin was associated with a marked decrease in renal phosphatase that occurred within 24 hours.

Rats. The normal kidney of the SpragueDawley rat contains an abundance of phosphatase, as seen in Figure 6. When sublethal amounts of endotoxin were given into the tail vein of this strain of rats there was no gross or microscopic evidence of a decrease in phosphatase. It is significant that the adult rat proved to be very resistant to endotoxin, but when a large dose of endotoxin (10 mg per $250 \mathrm{~g}$ ) was given intravenously, a uniform sequence of events occurred. The outstanding feature was a severe degree of vasoconstriction that occurred within 20 minutes after the endotoxin had been injected. The ears and feet appeared marble-white, instead of the usual pink color. Within another ten minutes the pinkness returned, which was gradually followed

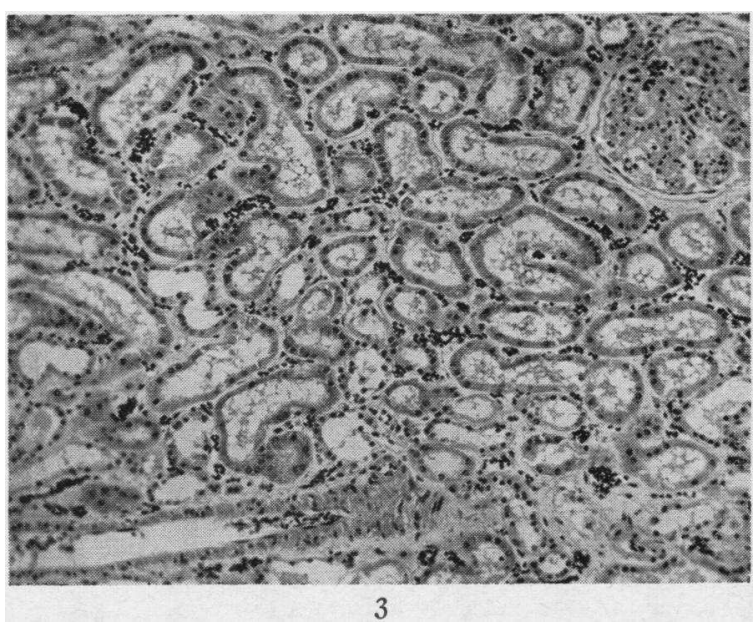

Fig. 3. Minimal Changes in Kidney of young ADULT WHO DIED AS RESULT OF SHOCK AND ANURIA 60 HOURS AFTER RECEIVING TRANSFUSION CONTAMINATED WITH PARACOLOBACTRUM AEROGENOIDES. Slight dilatation of the proximal convoluted tubules is noted. Hematoxylin and eosin stain, $\times 100$ (courtesy of Dr. Wendell Hall).
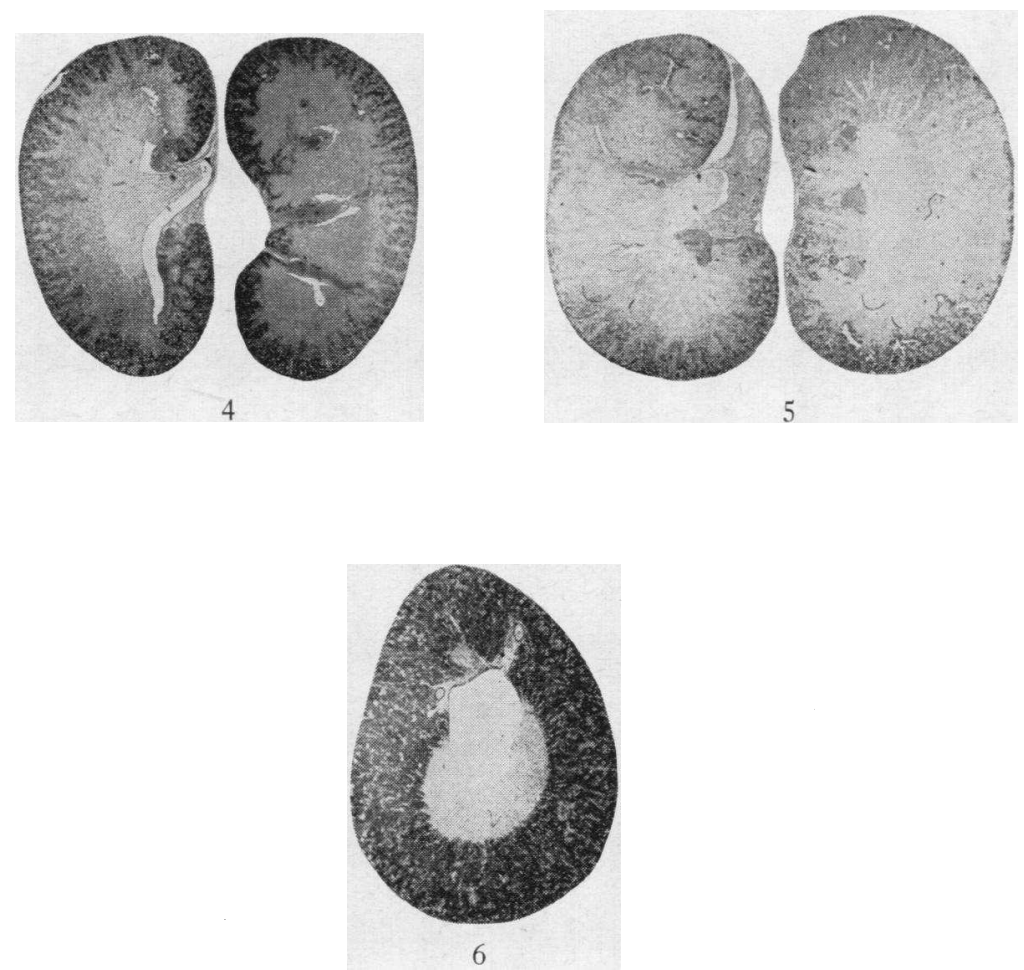

Fig. 4. Distribution of PhOSPhatase in NORMal Kidney of SwissWEBSTER MOUSE; $\times 5.5$.

Fig. 5. Marked diminution of phosphatase in kidney of SwissWEBSTER MOUSE 16 HOURS AFTER INJECTION OF ENDOTOXIN, $\times 5.5$.

Fig. 6. Distribution of Phosphatase in NORMAl kidney of Sprague- 
by cyanosis and death of the animals within five hours. Autopsy revealed a hemorrhagic mucosa of the intestinal tract. The hematoxylin and eosin preparations of kidney showed no morphologic changes. The phosphatase stain did not reveal any consistent decrease in the amount of phosphatase, but under close microscopic examination there was a segmental disappearance of phosphatase in some areas of the cortex as compared with the normal control. It was concluded from this acute experiment that the severe vasoconstriction resulting from the endotoxin involved the kidney, and ischemia and anoxia affected some parts of the kidney more than others. This vasoconstriction was associated with a segmental depletion of phosphatase.
Guinea pigs. This species was also found to be quite resistant to the lethal action of endotoxin, and preparations of kidney from normal animals revealed a rich deposit of phosphatase in the tubules of the cortex. Phosphatase studies were carried out on ten animals injected intraperitoneally with endotoxin. When the animals were sacrificed 24 hours after having received $1.5 \mathrm{mg}$ per $\mathrm{kg}$ of endotoxin, no morphologic alterations were seen with the hematoxylin and eosin stain, and other fixed sections showed no consistent reduction in phosphatase. When examined microscopically, the segmental diminution of phosphatase observed in the kidneys of rats was also demonstrated in the kidneys of the guinea pigs.

Rabbits. Our experience with rabbits in the
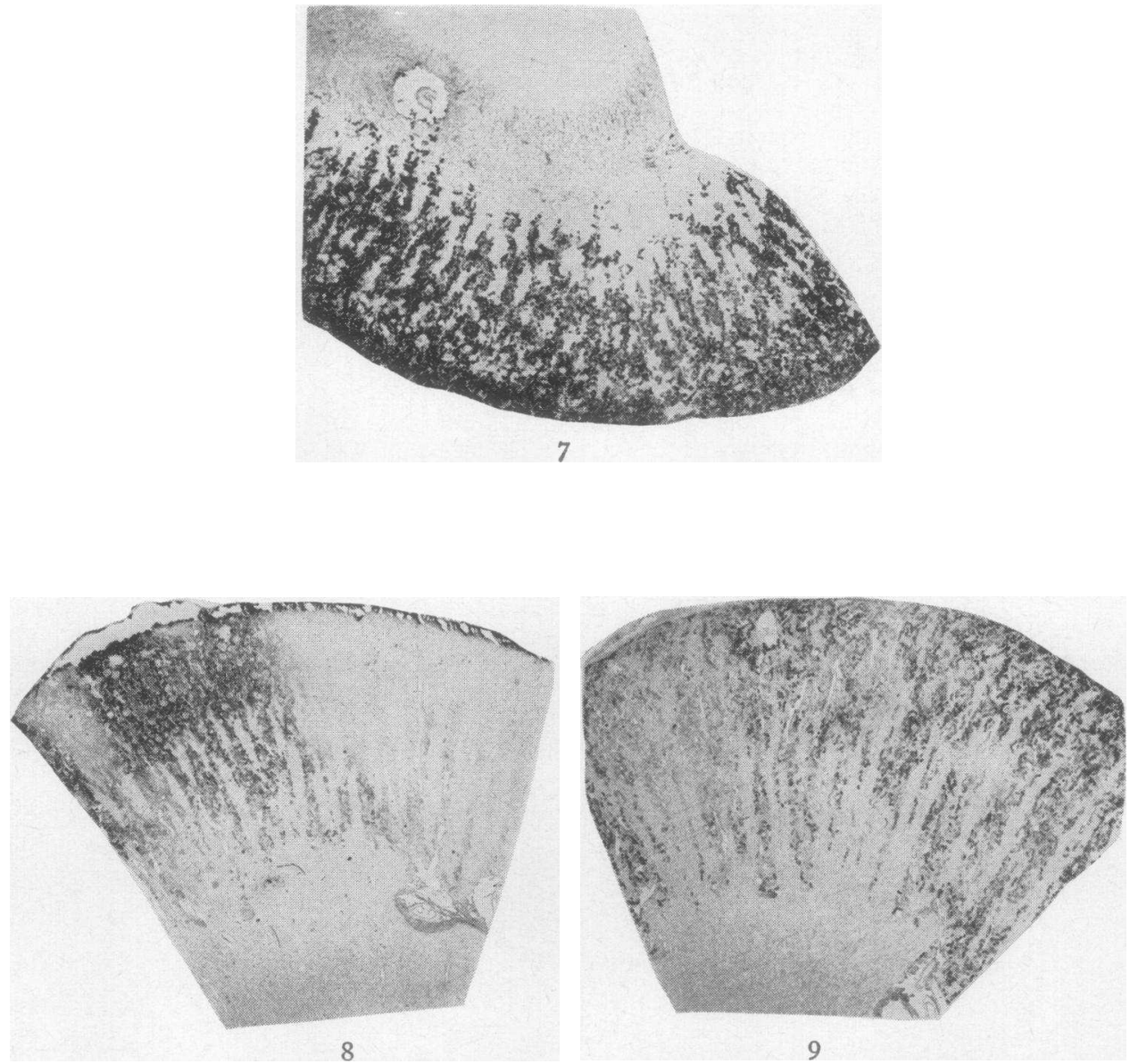

Fig. 7. Phosphatase in NORMal Kidney of DOG; $\times 5.5$.

Fig. 8. Segmental decrease in phosphatase of KIDNEY From dog 24 hours After RECEIVING ENDOTOXIN ; $\times 5.5$.

Fig. 9. DECREASE IN PHOSPHATASE OF KIDNEY FROM DOG SACRIFICED TWO HOURS AFTER RECEIVING ENDOTOXIN ; $\times 5.5$. 
overall study of the hemodynamic changes resulting from endotoxin has been inconsistent and disappointing. This is due to the fact that this species "is notorious for the lability of its vasomotor and renal function" (14). In a study in eight rabbits it was possible to demonstrate the same segmental decrease in tubular phosphatase following endotoxin as was noted in rats and in guinea pigs. This was particularly noted in the kidneys of rabbits that had died eight hours after having received an intravenous dose of endotoxin ( $5 \mathrm{mg}$ per $\mathrm{kg}$ ).

Dogs. We have found dogs satisfactory for the study of certain hemodynamic effects of endotoxin, which included morphologic and functional investigations on the kidney. This species is comparatively sensitive to endotoxin. In one series of experiments involving six dogs an intravenous dose of $0.1 \mathrm{mg}$ of endotoxin per $\mathrm{kg}$ produced death in two animals within two to six hours. In the present study on renal failure 27 dogs were employed. When the left kidney was exposed through an abdominal incision in the intact dog, a prompt contraction in the size of the kidney was detected within a few minutes after the injection of endotoxin. Contraction of the spleen also occurred. The manifestation of renal vasoconstriction was simultaneously associated with a diminution in urinary flow. Continuous observations revealed that the initial period of severe renal vasoconstriction was followed in one to two hours by vasodilation, which was particularly obvious in the renal vein.

It was significant how quickly the amount of renal phosphatase was decreased after the injection of endotoxin. Figure 7 demonstrates the phosphatase in the kidney of the normal dog. Figure 8 is representative of the segmental decrease in enzyme in the kidney of a dog that developed shock following the injection of endotoxin, but which subsequently recovered. The animal was sacrificed 24 hours after receiving the endotoxin. But more remarkable was the segmental diminution of phosphatase in a dog sacrificed two hours after receiving endotoxin (Figure 9). The dog was in a state of severe shock when sacrificed and undoubtedly would have expired within a short time. Just before the animal was sacrificed direct observations were made of the kidney through an incision. The renal vein appeared dilated, while the renal arery was very constricted. Immediately after removing a kidney the cut surface of the renal cortex looked very pale. No other gross changes were apparent.

Although all of the dogs that had received endotoxin showed a diminution in the amount of renal phosphatase, all of these dogs had exhibited shock before death, and all of the kidneys were studied within 24 hours after the injection of endotoxin. No morphologic changes were seen in sections of kidney stained with hematoxylin and eosin.

\section{Attempts to relate diminution of renal phosphatase to anoxia}

Twelve normal Swiss-Webster mice were sacrificed. The kidneys of one animal were immediately removed, sectioned and stained for phosphatase. One kidney from each remaining mouse was kept in a sterile container at room temperature, and the other at $37^{\circ} \mathrm{C}$. At intervals of 24 hours, a kidney maintained at room temperature, and another at $37^{\circ} \mathrm{C}$ were sectioned and stained for alkaline phosphatase. At the end of 120 hours the paired kidneys revealed the presence of severe postmortem changes and necrosis, but contained the same amount of phosphatase as those kidneys removed and stained immediately after death. Anoxia, per se, is apparently not the only factor responsible for the decrease in the amount of phosphatase.

\section{DISCUSSION}

This investigation has shown that there is a reduction in demonstrable alkaline phosphatase in human kidneys following hemorrhagic shock, chronic glomerular nephritis, shock due to myocardial infarction, and shock associated with severe sepsis. Furthermore, when endotoxin was injected into mice, rats, guinea pigs, rabbits and dogs, a decrease in renal phosphatase was observed as early as two hours after the endotoxin had been given to dogs and within 24 hours in all of the other species. The renal failure that is induced by endotoxin is accompanied by a prompt reduction in renal blood flow. The reduced blood flow is associated with renal vasoconstriction and with decreased cardiac output. Anoxia, which results from these hemodynamic changes, un- 
doubtedly plays an important role in renal failure.

We have no evidence at all that the endotoxin is directly responsible for the decrease. The question arises as to whether or not anoxia is the primary cause for the decrease in alkaline phosphatase. The enzyme is concentrated in the proximal convoluted tubules, which possess a high degree of metabolic activity. It is well established that tubular function, as well as that of the rest of the nephrons, is depressed by anoxia. It has been pointed out that the reversibility or irreversibility of renal failure following a state of anoxia is dependent upon the duration of time in which renal blood flow has been impaired (15). It has been recorded that the kidneys of both the dog and man can be deprived of their blood supply for up to 90 minutes and, with the resumption of blood flow, function can be restored (16). Constriction of the renal artery in the rabbit for 60 to 120 minutes will result in degenerative changes in the proximal convoluted tubules (17). While the severe vasoconstriction and ensuing anoxia can be causally related to the impaired renal function, the precise mechanism for the decrease in alkaline phosphatase is not understood. That anoxia, per se, is not directly responsible is supported by the studies on the kidneys of mice which had been dead for several days. The kidneys of mice that had been dead for five days revealed the same abundance of phosphatase as that observed in the kidneys removed and stained immediately after death. The most likely explanation for the decrease in phosphatase is a derangement of renal metabolic activity resulting from the anoxia. Hoare and Delory (18) have shown that sodium cyanide inhibits alkaline phosphatase in the human kidney, and the phosphatase can be reactivated by magnesium and zinc ions. This suggests that renal phosphatase may be inactivated through a mechanism of defective intracellular oxidation.

We have been unable to quantitate any disturbance in renal function, as a result of endotoxin shock, that could be correlated with a diminution in phosphatase. In a comprehensive discussion on phosphatase Roche (19) has stated, "Although it is not actually possible to state precisely the mechanism of action of alkaline phosphatase in kidney secretion, its abundance and its localization at least suggest that the enzyme takes part in the tubular resorption of glucose, probably in the de- phosphorylating phase." In support of this he states that the toadfish, Opsanus tau, is an aglomerular animal that contains no tubular phosphatase and neither secretes nor excretes sugar. However, others (20) have examined a wide variety of aglomerular marine teleosts and have found alkaline phosphatase in the brush borders of the "proximal" segment. They concluded that the enzyme could not function only in the absorption of glucose from the glomerular filtrate. Utilizing a microanalytic technique, Pollak, Bonting, Muehrcke and Kark (21) could not find a correlation between glucose reabsorption and phosphatase in the human kidney. In phlorizin glycuresis in the cat and dog having acute and chronic phlorizin poisoning there is no diminution in alkaline phosphatase (22). It is significant that glycosuria is not a prominent feature in either patients or in experimental animals having severe endotoxin shock.

The diminution of renal phosphatase from the mammalian kidney as a result of endotoxin shock would indicate that the enzyme is released from the tissues into the blood stream, and elevated blood concentrations of phosphatase should be encountered. We have observed marked increases in the levels of alkaline phosphatase in rabbits and in dogs as a result of endotoxin shock. Smith, Keppie, Stanley and Harris-Smith (23) and Ross (24) also found elevated levels of alkaline phosphatase in the blood of guinea pigs whose kidneys showed the loss of phosphatase because of shock due to anthrax. It is not unlikely that the elevated phosphatase levels in the blood are derived from other tissues as well as from the blood. In anthrax shock of guinea pigs, the concentrations of alkaline phosphatase were also increased in the urine.

The present studies emphasize the severe functional impairment that can occur in shock without demonstrable morphologic changes in the involved tissues. Severe and irreversible renal failure takes place through mechanisms that are little understood. The marked depletion of alkaline phosphatase in a brief period of time, which can be correlated with grave functional disturbances, suggests that further studies on renal enzyme systems might be fruitful toward a better understanding of irreversible renal failure that occurs in shock. 


\section{SUM MARY}

1. The demonstration of alkaline phosphatase in the kidneys of several representatives of the mammalian species, including man, was readily carried out with a modified histochemical technique of Gomori. A decrease in phosphatase was noted in the kidneys of patients dying from various forms of shock. Endotoxin shock was produced in the mouse, rat, guinea pig, rabbit and dog. A segmental decrease in renal phosphatase was observed in the kidneys of each of these species, although morphologic changes could not be demonstrated in sections stained with hematoxylin and eosin.

2. Previous experiments had revealed that renal failure in endotoxin shock was caused by vasoconstriction and by a reduced blood flow, which resulted in anoxia and a cessation of urine flow. The vasoconstriction is segmental, and this is correlated with a segmental disappearance of phosphatase from the kidney.

3. The function of renal phosphatase is not understood. The present investigations suggest that endotoxin shock results in a defective mechanism of intracellular oxidation in the kidney which results in the loss of phosphatase.

\section{REFERENCES}

1. Delaunay, A., Boquet, P., Lebrun, J., Lehoult, Y., and Delaunay, M. Le mode d'action des endotoxines bactériennes. II. Les troubles vaso-moteurs chez les animaux intoxiqués et leurs conséquences. J. Physiol. (Paris) 1948, 40, 89.

2. Hinshaw, L. B., and Bradley, G. M. Alterations in kidney weight produced by Escherichia coli endotoxin. Amer. J. Physiol. 1957, 89, 329.

3. Hinshaw, L. B., Bradley, G. M., and Carlson, C. H. The effect of endotoxin on renal function in the dog. Amer. J. Physiol. 1959, 196, 1127.

4. Block, M. A., Wakim, K. G., Mann, F. C., and Bennett, W. A. Renal lesions and function following prolonged experimental hypertension. Surgery 1952, 32, 551.

5. Van Slyke, D. D., Phillips, R. A., Hamilton, P. B., Archibald, R. M., Dole, V. P., and Emerson, K., Jr. Effect of shock on the kidney. Trans. Ass. Amer. Phycns 1944, 58, 119.

6. Brun, C., and Munck, O. Lesions of the kidney in acute renal failure following shock. Lancet 1957, 1,603 .

7. Gomori, G. Distribution of phosphatase in normal organs and tissues. J. cell. comp. Physiol. 1941, 17,71 .
8. McManus, J. F. A. Medical Diseases of Kidney. Philadelphia, Lea and Febiger, 1950.

9. Beyer, K. H. Functional characteristics of renal transport mechanisms. Pharmacol. Rev. 1950, 2, 227.

10. Brain, R. T., and Kay, H. D. Kidney phosphatase. II. The enzyme in disease. Biochem. J. 1927, 21, 1104.

11. McManus, J. F. A., and Mowry, R. W. The distribution of alkaline phosphatase in some abnormal human kidneys. Bull. int. Ass. med. Mus. 1948, 28, 80.

12. Wilmer, H. A. Disappearance of phosphatase from the hydronephrotic kidney. J. exp. Med. 1943, 78, 225.

13. Lillie, R. D. Histopathologic Technic and Practical Histochemistry. New York, McGraw-Hill Book Co., Blakiston Div., 1954, p. 202.

14. Robinson, J. R. Reflections on Renal Function. Oxford, Blackwell Scientific Publications, 1954, p. 43.

15. Van Slyke, D. D. Renal tubular failure of shock and nephritis. Ann. intern. Med. 1954, 41, 709.

16. Bricker, N. S., Stokes, J. M., Lubowitz, H., Dewey, R. R., Bernard, H. R., and Hartroft, P. M. Experimentally induced permanent unilateral renal disease in dogs. J. Lab. clin. Med. 1958, 52, 571.

17. Scarff, R. W., and Keele, C. A. The effects of temporary occlusion of the renal circulation in the rabbit. Brit. J. exp. Path. 1943, 24, 147.

18. Hoare, R., and Delory, G. E. The effect of zinc and magnesium ions on the activity of kidney alkaline phosphatase. Arch. Biochem. 1955, 59, 465.

19. Roche, J. The Phosphatases in The Enzymes: Chemistry and Mode of Action, J. B. Sumner and K. Myrbäck, Eds. New York, Academic Press Inc., 1950 , vol. 1 , pt. 1 , p. 473.

20. Browne, M. J., Pitts, M. W., and Pitts, R. F. Alkaline phosphatase activity in kidneys of glomerular and aglomerular teleosts. Biol. Bull. 1956, 99, 152.

21. Pollak, V. E., Bonting, S. L., Muehrcke, R. C., and Kark, R. M. Quantitative measurement of alkaline phosphatase and lactic dehydrogenase activities in the anatomic units of the human nephron (abstract) J. Lab. clin. Med. 1958, 52, 934.

22. Kritzler, R. A., and Gutman, A. B. "Alkaline" phosphatase activity of the proximal convoluted tubules and the mechanism of phlorizin glycuresis. Amer. J. Physiol. 1941, 134, 94.

23. Smith, H., Keppie, J., Stanley, J. L., and HarrisSmith, P. W. The chemical basis of the virulence of Bacillus anthracis. IV. Secondary shock as the major factor in death of guinea-pigs from anthrax. Brit. J. exp. Path. 1955, 36, 323.

24. Ross, J. M. On the histopathology of experimental anthrax in guinea-pig. Brit. J. exp. Path. 1955, $36,336$. 